\title{
Surgical Management of Perforated Peptic Ulcer; Closure with Omental Patch versus Definitive Repair with Vagotomy and Gastrojejunostomy: A Comparative Study
}

\author{
Walid A. Mawla', Ibrahim A. Heggy', Gamal Osman¹, Loay M. Gertallah¹, Marwan N. Elgohary², \\ Ahmed S. Allam², Ahmed M. Elsayed ${ }^{3}$, Heba F. Tantawy ${ }^{4}$ \\ ${ }^{1}$ Department of General Surgery, Faculty of Medicine, Zagazig University, Zagazig, Egypt \\ ${ }^{2}$ Department of Internal Medicine, Faculty of Medicine, Zagazig University, Zagazig, Egypt \\ ${ }^{3}$ Department of Tropical Medicine, Faculty of Medicine, Zagazig University, Zagazig, Egypt \\ ${ }^{4}$ Department of Radiology, Faculty of Medicine, Zagazig University, Zagazig, Egypt \\ Email: loayelhady@gmail.com
}

How to cite this paper: Mawla, W.A., Heggy, I.A., Osman, G., Gertallah, L.M., Elgohary, M.N., Allam, A.S., Elsayed, A.M. and Tantawy, H.F. (2019) Surgical Management of Perforated Peptic Ulcer; Closure with Omental Patch versus Definitive Repair with Vagotomy and Gastrojejunostomy: A Comparative Study. Surgical Science, 10, 316-327.

https://doi.org/10.4236/ss.2019.109035

Received: August 25, 2019

Accepted: September 20, 2019

Published: September 23, 2019

Copyright (๑) 2019 by author(s) and Scientific Research Publishing Inc. This work is licensed under the Creative Commons Attribution International License (CC BY 4.0).

http://creativecommons.org/licenses/by/4.0/ (c) (i) Open Access

\begin{abstract}
Background: The perforation of peptic ulcer is a common and serious life threatening surgical emergency. Up-till now no consensus was reached regarding the best practice in management of perforated peptic ulcer. The aim of this study is to evaluate and compare between both management strategies of perforated peptic ulcer; performing simple closure of the perforation with an omental patch then $H$. pylori eradication and inhibition of acid secretion using long time proton pump inhibitors versus performing definitive repair of perforated peptic ulcer (closure of the perforation with an omental patch, truncal vagotomy and gastrojejunostomy to discover a proper management strategy of perforated peptic ulcer. Patients and Methods: In the current study we included 30 patients which were divided into 2 groups: group 1 included 15 patients where we managed them by simple closure of the perforation with an omental patch then $H$. pylori eradication and inhibition of acid secretion using long time proton pump inhibitors and group 2 included 15 patients where we performed closure of the perforation with an omental patch, truncal vagotomy and gastrojejunostomy. Results: We found that younger patient underwent vagotomy and gastro-jejunostomy technique $(\mathrm{p}<$ 0.001 ), the technique of vagotomy and gastro-jejunostomy has a longer duration than closure with omental patch acid reduction $(\mathrm{p}=0.009)$. There was a highly statistically significant association between both surgical procedures regarding; duration of hospital stay (longer in case of definitive repair) ( $\mathrm{p}<$ 0.001). Conclusions: Peptic ulcer perforation could be safely managed by
\end{abstract}


primary closure and covering by omentum in addition to medical treatment of $H$. pylori infection and inhibition of acid secretion especially in old patients with comorbid condition who presented late or with shock.

\section{Keywords}

Perforated Peptic Ulcer, Omental Patch, Vagotomy, Gastrojejunostomy

\section{Introduction}

The perforation of peptic ulcer is a common and serious life threatening surgical emergency. There are many management modalities but, up-till now no consensus was reached regarding the best practice in management of perforated peptic ulcer. Perforated peptic ulcer could be managed conservatively, by simple closure of the perforation using omental patch or definitive management by performing truncal vagotomy and drainage operation: gastrojejunostomy [1]. Conservative management of perforated peptic ulcer has a limited role [2]. It was previously suggested that exploratory laparotomy is indicated within twelve hours if signs of peritonitis are present to avoid serious complications [3]. There are various available surgical options and their choice depends on many parameters such as duration of peritonitis, previous history of peptic ulcer disease symptoms, size of perforation and presence of co-morbid conditions [4]. It was previously stated that definitive surgical management of the perforated ulcer could be performed if there was a minimal contamination of the upper abdomen and the patient was stable having no severe co-morbid conditions. This definitive surgical management includes vagotomy and gastro-jejunostomy [5] [6]. Due to recent advances in medical anti-ulcer therapies, simply closing the perforation site using omental patch which is followed by $H$. pylori eradication and inhibition of acid secretion by proton pump inhibitors are safe and easy options which changed the past concept of using truncal vagotomy and drainage procedures [7].

The aim of this study is to evaluate and compare between both management strategies of perforated peptic ulcer: performing simple closure of the perforation with an omental patch then $H$. pylori eradication and inhibition of acid secretion using long time proton pump inhibitors and performing definitive repair of perforated peptic ulcer (closure of the perforation with an omental patch, truncal vagotomy and gastrojejunostomy) regarding the indications, benefits, disadvantages, operative risks and post-operative complications to discover a proper management strategy of perforated peptic ulcer for their management and to achieve better early and long term results.

\section{Patients and Methods}

This prospective study was performed in General Surgery Department, Zagazig 
University Hospitals, Internal Medicine Department, Tropical Medicine Department and Radiology Department, Faculty of Medicine, in the period from May 2018 to May 2019.

We included 30 patients which were diagnosed as having perforated peptic ulcer clinically and radiologically.

We decided the sample size according to number of admitted patients to Department of Surgery, Zagazig University Hospitals.

Patients which were divided into 2 groups; group 1 included 15 patients where we managed them by closing the perforation site with an omental patch then $H$. pylori eradication and inhibition of acid secretion using long time proton pump inhibitors and group 2 included 15 patients where we performed closure of the perforation with an omental patch, truncal vagotomy and gastrojejunostomy. Then we have followed our patients by upper gastrointestinal endoscopy to detect post-operative outcome, long term recovery and complication.

\subsection{Inclusion Criteria}

Patients with perforated peptic ulcer were included in the study.

\subsection{Exclusion Criteria}

We have excluded; patients having incomplete data, patients with multiple perforations, patients with traumatic perforations, patients with previous gastric surgery and gastric outlet obstruction that caused by cancer and patients who have not performed postoperative upper gastrointestinal endoscopy.

\subsection{For All Included Patients}

The data of patients were taken from patient files in the General Surgery and Internal Medicine departments and enrolled in the study after taking a signed a written informed consent was taken from all the studied cases. We have taken a detailed history from the patients, examined all of them then performed laboratory investigations like complete blood count, serum urea and creatinine and random blood sugar in Clinical Pathology Department, Faculty of Medicine, Zagazig University. We make the radiological investigations as; X-ray abdomen erect and chest X-ray for all studied patients if there is suspicion of perforated peptic ulcer disease in Radiology Department, Faculty of Medicine, Zagazig University. Diagnosis of perforated peptic ulcer was made from history, plain X-ray abdomen and chest then confirmed after performing laparotomy. Included patients were put on intravenous fluids, nasogastric suction, intravenous anti-ulcer drugs and intravenous antibiotics detecting adequate degree of hydration was made by an hourly assessment of urine output of $30-50 \mathrm{ml} /$ hour.

\subsection{For Patients in the First Group: [7]}

After performing adequate resuscitation procedures, we performed laparotomy through a midline incision. Identification of site and size of the perforation was 
done. We made freshening of the perforation margins and the removed tissue is taken as a biopsy for all cases. We placed many full thickness simple silk sutures across the perforation then we placed a pedicled omentum over the site of perforation. We could test the repair by putting warm saline in peritoneal cavity and air insufflation into stomach by the nasogastric tube; if we found that there is no air leakage that means the perforation has been sealed. We made a through peritoneal washing with 3 to 4 liters of warm saline then we placed two intra-peritoneal drains; one is placed in hepatorenal (Morrison's) pouch and the other is placed in the pelvic cavity. Finally, we closed the midline incision using mono-filamentous suture in a single layer.

We keep patients Nil by mouth up to four days then patients are allowed orally once the peristalsis returns by clear fluid and then by taking soft to solid diet. We removed the drains post-operatively when patient thriving and when each drain provides less than $30 \mathrm{ml}$. we checked the dressing on post-operative day 3 and regularly until we removed sutures. We put all included patients on triple regime that is composed of Amoxicillin (500 mg TID), Omeprazole (20 mg BID) and Metranidazole (400 mg TID) orally for 14 days to treat H. pylori, and decrease gastric acidity in the post-operative period. We followed-up the patients on by upper GIT endoscopy after surgery for up to 12 months after surgery.

\subsection{For Patients in the Second Group: Figures 1(a)-(c)}

After performing adequate resuscitation procedures, we performed laparotomy through a midline incision. Identification of site and size of the perforation was done. We made freshening of the perforation margins and the removed tissue is taken as a biopsy for all cases. We placed many full thickness simple silk sutures across the perforation then we placed a pedicled omentum over the site of perforation. We could test the repair by putting warm saline in peritoneal cavity and air insufflation into stomach by the nasogastric tube; if we found that there is no air leakage that means the perforation has been sealed. We made a through peritoneal washing with 3 to 4 liters of warm saline then we placed two intra-peritoneal drains; one is placed in hepatorenal (Morrison's) pouch and the other is placed in the pelvic cavity.

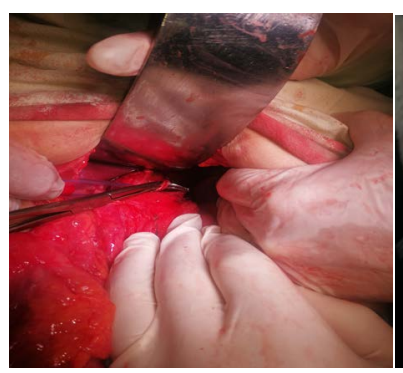

(a)

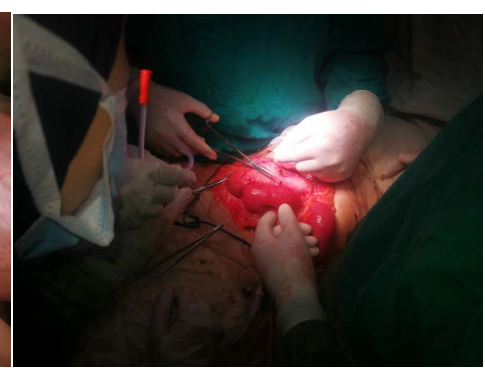

(b)

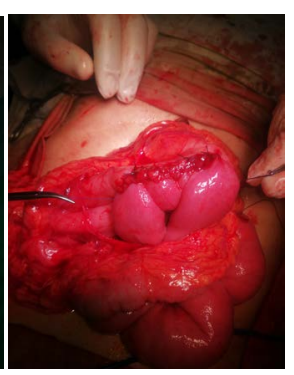

(c)

Figure 1. Intra-operative steps of truncal vagotomy and gastrojejunostomy (a) Truncal vagotomy (b) \& (c) Gastrojejunostomy. 
After we have retracted the left liver lobe of the liver by a sternal retractor and exposed the lesser sac of omentum we identify the vagus nerve which is located next to the gastric lesser curve then we have pulled it laterally using a tape and divide its anterior and posterior branches.

We have approximated serosal layers which is located on both anterior and posterior sides of the lesser curve using interrupted sutures. We have performed gastrojejunostomy in two layers using continuous sutures, on the posterior stomach wall trough the meso-colon of the transverse colon about $20-30 \mathrm{~cm}$ from the Treitz ligament. We reconstructed angle of His in all the patients using two or three interrupted sutures. We followed up all patients yearly by clinical examination and by performing upper gastrointestinal endoscopy 1 and 3 years after the surgery to assess the following data; ulcer or erosions formation, formation of a liquid "pool" which is considered a sign for delayed emptying of the stomach, stricture in the pyloric canal or the presence of bile [8].

\section{Statistical Analysis}

Data analysis was done by the software SPSS (Statistical Package for the Social Sciences) program version 20. We have described quantitative data by using means and standard deviations, described categorical data by using the absolute frequencies and compared them by using Chi square test. Independent sample $t$ test was used to compare means of two groups. The level statistical significance was set at $5 \%(\mathrm{p}<0.05)$.

\section{Results}

\subsection{Demographic and Pre-Operative Results: Table 1; Figure 1 and Figure 2}

The present study included 30 patients with perforated peptic ulcer which were managed over a year. Their age ranged from 20 to 51 years with a mean age of $36.1 \pm 8.88$ years. There were $27(90 \%)$ male patients and $3(10 \%)$ female patients. All patients were presented with past history of acute pain in the epi-gastric region. There are 15 (50\%) male patients have history of smoking.

The plain X-ray abdomen of most included patients in erect position revealed the presence of free gas under diaphragm.

There is statistically significant difference between patients underwent different surgical techniques regarding age, as younger patient who afford definitive surgery underwent vagotomy and gastro-jejunostomy technique, while older patients underwent closure with omental patch and acid reduction $(\mathrm{p}<0.001)$ and duration of perforation, as the technique of vagotomy and gastro-jejunostomy has a longer operative duration than closure with omental patch acid reduction technique $(\mathrm{p}=0.009)$.

\subsection{Post-Operative Results: Table 2, Figures 2-4}

There was a highly statistically significant association between both surgical 
Table 1. Comparison between the studied surgical techniques regarding demographic and operative data.

\begin{tabular}{|c|c|c|c|c|}
\hline \multirow{3}{*}{ Variables } & \multirow[b]{2}{*}{ Total } & \multicolumn{2}{|c|}{ Surgical techniques } & \multirow{3}{*}{$\mathrm{p}$} \\
\hline & & $\begin{array}{l}\text { Closure with acid } \\
\text { reduction }\end{array}$ & $\begin{array}{c}\text { Vagotomy and } \\
\text { gastro-jejunostomy }\end{array}$ & \\
\hline & $\mathrm{N}=30(\%)$ & $\mathrm{N}=15(\%)$ & $\mathrm{N}=15(\%)$ & \\
\hline \multicolumn{5}{|l|}{ Age (years): } \\
\hline Mean \pm SD & $36.1 \pm 8.88$ & $42 \pm 5.84$ & $30.2 \pm 7.38$ & $<0.001^{\star x}$ \\
\hline Range & $20-51$ & $34-51$ & $20-45$ & \\
\hline \multicolumn{5}{|l|}{ Gender: } \\
\hline Male & $27(90)$ & $13(86.7)$ & $14(93.3)$ & 1 \\
\hline Female & $3(10)$ & $2(13.3)$ & $1(6.7)$ & \\
\hline \multicolumn{5}{|l|}{ Smoking: } \\
\hline Absent & $15(50)$ & $10(66.7)$ & $5(33.3)$ & 0.143 \\
\hline Present & $15(50)$ & $5(33.3)$ & $10(66.7)$ & \\
\hline \multicolumn{5}{|l|}{ Alcoholism: } \\
\hline Absent & $24(80)$ & $13(54.2)$ & $11(45.88)$ & 0.651 \\
\hline Present & $6(20)$ & $2(33.3)$ & $4(66.7)$ & \\
\hline \multicolumn{5}{|l|}{ Comorbid condition: } \\
\hline Absent & $20(66.7)$ & $8(40)$ & $12(60)$ & 0.245 \\
\hline Present & $10(33.3)$ & $7(70)$ & $3(30)$ & \\
\hline \multicolumn{5}{|l|}{ Clinical presentation: } \\
\hline \multicolumn{5}{|l|}{ Severe abdominal pain and } \\
\hline distension & $8(26.7)$ & $3(37.5)$ & $5(62.5)$ & 0.242 \\
\hline Nausea, vomiting, dyspepsia & $11(36.7)$ & $4(36.4)$ & $7(63.6)$ & \\
\hline Fever and shock & $5(16.7)$ & $3(60)$ & $2(40)$ & \\
\hline Classical signs of peritonitis & $6(20)$ & $5(83.3)$ & $1(16.7)$ & \\
\hline \multicolumn{5}{|l|}{ Preoperative shock: } \\
\hline Absent & $19(63.3)$ & $7(36.8)$ & $12(63.2)$ & 0.128 \\
\hline Present & $11(36.7)$ & $8(72.7)$ & $3(27.3)$ & \\
\hline \multicolumn{5}{|l|}{ Duration of perforation: } \\
\hline$<24$ hours & $14(46.7)$ & $3(21.4)$ & $11(78.6)$ & $0.009^{*}$ \\
\hline$>24$ hours & $16(53.3)$ & $12(75)$ & $4(25)$ & \\
\hline
\end{tabular}

${ }^{* *} \mathrm{p} \leq 0.001$ is statistically highly significant or ${ }^{*} \mathrm{p}<0.05$ is statistically significant. $\mathrm{t}$ independent sample $\mathrm{t}$ test.

procedures regarding; duration of operation, duration of hospital stay (longer in case of definitive repair) and use of post-operative drugs ( $\mathrm{p}<0.001)$.

On the other hand, there is non-significant difference between them regarding gender, smoking, alcoholism, clinical presentation, site, size of the ulcer, presence of post-operative leakage, post-operative mortality.

\section{Discussion}

In the current study, perforated peptic ulcer were mostly diagnosed in the $4^{\text {th }}$ decade of life and affects males more than females, mostly due to excessive 
Table 2. Comparison between the studied surgical techniques regarding operative and postoperative data.

\begin{tabular}{|c|c|c|c|c|}
\hline \multirow{3}{*}{ Variables } & \multirow[b]{2}{*}{ Total } & \multicolumn{2}{|c|}{ Surgical techniques } & \multirow{3}{*}{$\mathrm{p}$} \\
\hline & & $\begin{array}{l}\text { Closure with } \\
\text { acid reduction }\end{array}$ & $\begin{array}{c}\text { Vagotomy and } \\
\text { gastro-jejunostomy }\end{array}$ & \\
\hline & $\mathrm{N}=30(\%)$ & $\mathrm{N}=15(\%)$ & $\mathrm{N}=15(\%)$ & \\
\hline \multicolumn{5}{|l|}{ Size of ulcer $(\mathrm{cm})$ : } \\
\hline$<3 \mathrm{~cm}$ & $28(6.7)$ & $15(53.6)$ & $13(46.4)$ & 0.483 \\
\hline$\geq 3 \mathrm{~cm}$ & $2(93.3)$ & $0(0)$ & $2(100)$ & \\
\hline \multicolumn{5}{|l|}{ Site of ulcer: } \\
\hline Prepyloric & $19(63.3)$ & $10(52.6)$ & $9(47.4)$ & \\
\hline Lesser curvature & $4(13.3)$ & $2(50)$ & $2(50)$ & 0.943 \\
\hline Antrum & $4(13.3)$ & $2(50)$ & $2(50)$ & \\
\hline Greater curvature & $3(10)$ & $1(33.3)$ & $2(66.7)$ & \\
\hline \multicolumn{5}{|c|}{ Duration of operation (hours): } \\
\hline Mean \pm SD & $1.47 \pm 0.45$ & $1.07 \pm 0.18$ & $1.87 \pm 0.23$ & $<0.001^{\star *}$ \\
\hline Range & $1-2$ & $1-1.5$ & $1.5-2$ & \\
\hline \multicolumn{5}{|c|}{ Duration of hospital stay (days): } \\
\hline Mean \pm SD & $9.37 \pm 1.5$ & $8.2 \pm 0.86$ & $10.53 \pm 0.99$ & $<0.001^{\star *}$ \\
\hline Range & $7-12$ & $7-9$ & $9-12$ & \\
\hline \multicolumn{5}{|l|}{ Postoperative leakage: } \\
\hline Absent & $23(76.7)$ & $11(47.8)$ & $12(52.2)$ & 1 \\
\hline Present & $7(23.3)$ & $4(57.1)$ & $3(42.9)$ & \\
\hline \multicolumn{5}{|l|}{ Postoperative drugs: } \\
\hline PPI + IV fluids + antibiotic & $15(50)$ & $15(100)$ & $0(0)$ & $<0.001^{\star *}$ \\
\hline IV fluids + antibiotic & $15(50)$ & $0(0)$ & $15(100)$ & \\
\hline \multicolumn{5}{|l|}{ Postoperative morbidity: } \\
\hline Absent & $18(60)$ & $9(50)$ & $9(50)$ & 1 \\
\hline Present & $12(40)$ & $6(50)$ & $6(50)$ & \\
\hline \multicolumn{5}{|l|}{ Postoperative mortality: } \\
\hline Absent & $25(83.3)$ & $13(52)$ & $12(48)$ & 1 \\
\hline Present & $5(16.7)$ & $2(40)$ & $3(60)$ & \\
\hline \multicolumn{5}{|l|}{ Need for reoperation: } \\
\hline Absent & $22(73.3)$ & $10(45.5)$ & $12(54.5)$ & 0.682 \\
\hline Present & $8(26.7)$ & $5(62.5)$ & $3(37.5)$ & \\
\hline \multicolumn{5}{|c|}{ Clinical cure without complication: } \\
\hline Absent & $10(33.3)$ & $2(20)$ & $8(80)$ & 0.05 \\
\hline Present & $20(66.7)$ & $13(65)$ & $7(35)$ & \\
\hline
\end{tabular}

${ }^{* *} \mathrm{p} \leq 0.001$ is statistically highly significant. ${ }^{*} \mathrm{p}<0.05$ is statistically significant. $\mathrm{t}$ independent sample $\mathrm{t}$ test.

smoking which is similar to results of older studies. In perforated peptic ulcer patients the presence of $H$. pylori infection ranged from $50 \%-80 \%$ and it was more relevant as a leading cause of perorated peptic ulcer in younger patients but in elderly patients using NSAIDs was a more significant cause [9]. We showed that the most important predictor of outcome following surgery for 


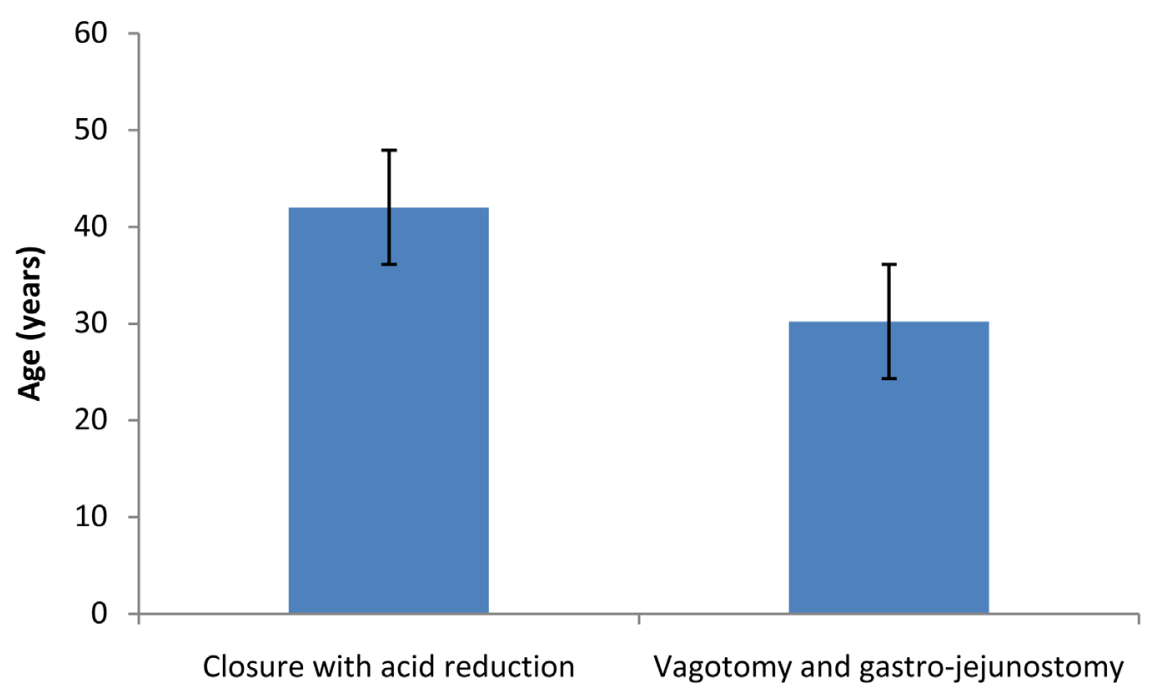

Figure 2. Simple bar chart showing comparison between the studied groups regarding age.

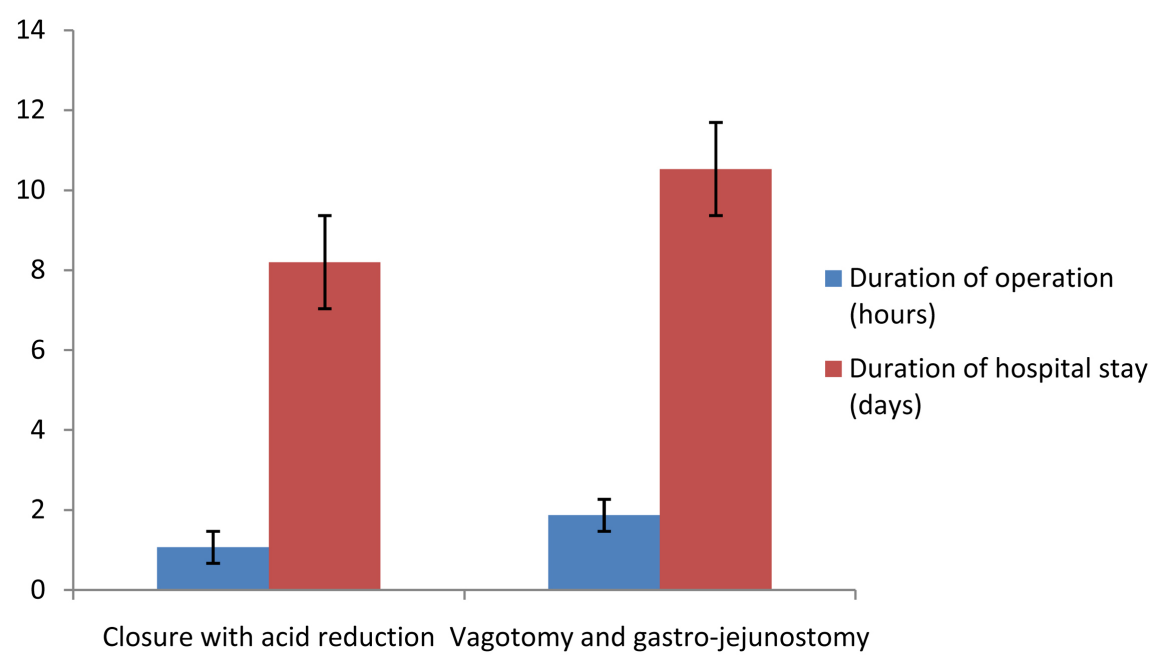

Figure 3. Combined bar chart showing comparison between the studied group regarding duration of operation and hospital stay.

perforated peptic ulcer was the duration between occurrence of perforation and initiation of treatment. In agreement with previous reports [10] [11], we have reached the diagnosis of perforated peptic ulcer in this study from history and radiological detection of free air under the diaphragm in plain chest and abdominal radiographs, but the accurate final diagnosis was reached at laparotomy [10].

There are many managing techniques for perforated peptic ulcer; even though, definitive surgery might be routinely or selectively performed in good risk patients, but management of patients that have recurrent, chronic, large ulcers or have $H$. pylori negative ulcers is still uncertain.

In the current study we have made a comparison between simple closure of the perforation with an omental patch then $H$. pylori eradication and inhibition 


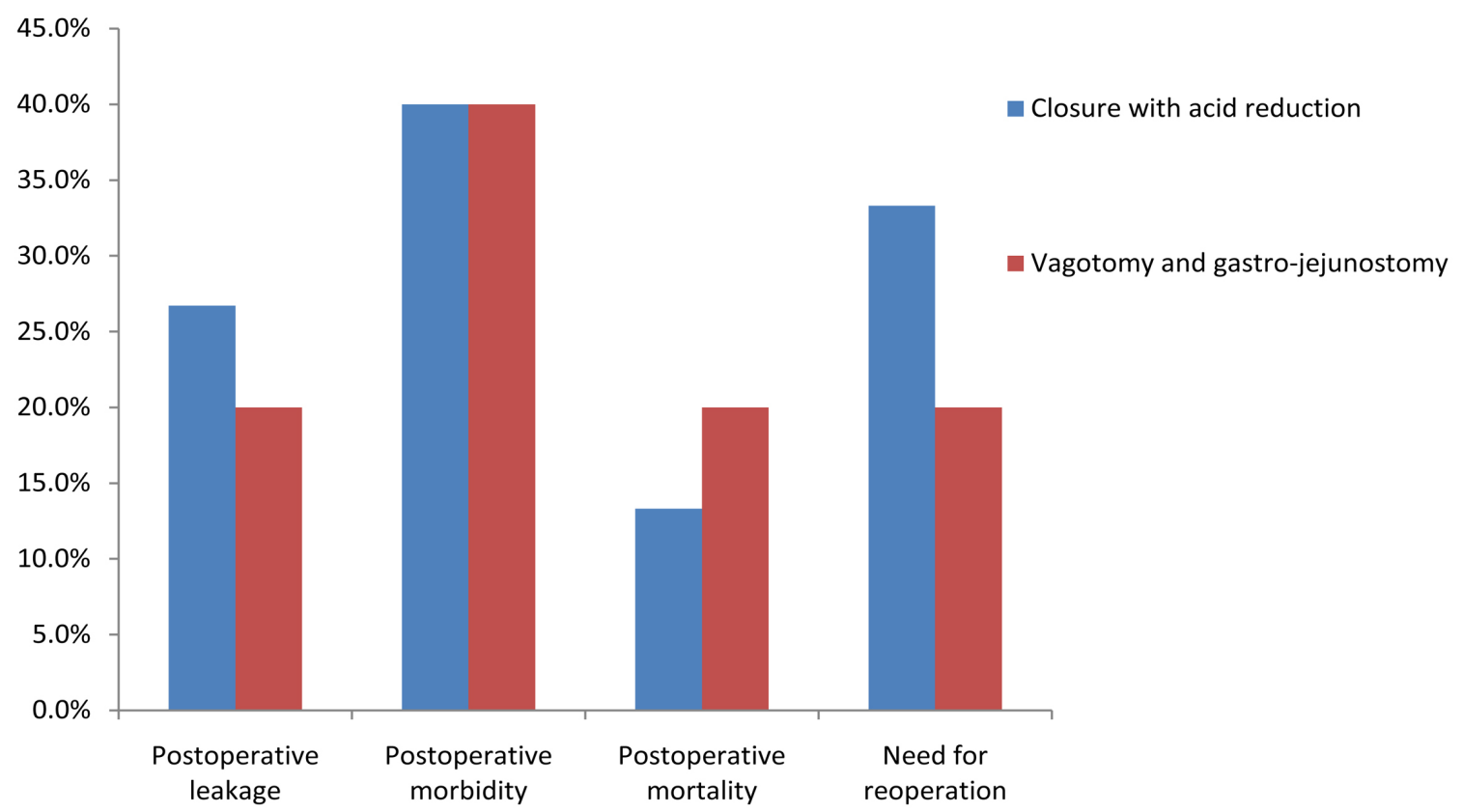

Figure 4. Combined bar chart showing comparison between the studied group regarding postoperative complications.

of acid secretion using long time proton pump inhibitors and closure of the perforation with an omental patch, truncal vagotomy and gastrojejunostomy. We have found that peptic ulcer perforation could be safely managed by primary closure and covering by omentum in addition to medical treatment of $H$. pylori infection and inhibition of acid secretion especially in old patients with comorbid condition who presented late or with shock. While, definitive ulcer surgery with closure of the perforation with an omental patch, truncal vagotomy and gastrojejunostomy is a better technique in young patients having no comorbid condition who presented early without signs of shock. Using vascularized pedicled omentum could help in sealing the perforation and neo-vascularization could accelerate healing of the ulcer and decrease incidence of recurrence [12]. The role of definitive surgery of perforated peptic has markedly declined due to advancement of medical therapy for eradication of $H$. pylori infection which resulted in a lower incidence of peptic ulcer disease and perforation. Additionally old, obese patients, patients with major co-morbidities who are unfit for definitive surgery and presence of surgeons with limited experiences contribute to decrease in definitive surgery usage for peptic ulcer disease. Similarly previous reports highlighted the role of using omental patch for closure of the perforation then used medical therapy for eradication of $\mathrm{H}$ pylori infection and inhibition of acid secretion and that routine gastroenterostomy could be unnecessary with many drawbacks [1] [7] [9] [13].

In the second group of our patients where we performed definitive surgery we found that it will be suitable for younger, fit patients having no major co-morbid conditions and in patients presented early and in case of absent preoperative shock or in the case of absence of co-morbid conditions. 
The control of acid production in definitive surgery is done by vagotomy and drainage procedure like gastrojejunostomy, similarly previous studies proved the benefits of performing definitive surgery [8] [14] [15].

Sealing with omental patch of the perforation was a rapid, easy and lifesaving surgical technique that was effective with lower incidence of mortality and morbidity. The disadvantage of such procedure is the high incidence of ulcer recurrence that was about $40 \%$ in some studies, but it was still the surgical procedure of choice in many centers which replaced the old technique of ulcer surgery; truncal vagotomy and drainage procedure [1] [7], and to avoid occurrence of ulcer recurrence the procedure is followed by H. pylori eradication [9].

But definitive surgery is still having its indications; in fit patients who presented to the hospital early seeking for surgery. The definitive peptic ulcer surgery disadvantages are; longer time of operation, exposure to prolonged anesthesia and increases postoperative complications risk [8] [15].

Vagotomy was described as a surgical revolutionary procedure that gave excellent results in decreasing rates of ulcer recurrence, but it had many undesirable side effects in about $50 \%$ of patients. The dissecting of vagal branches to the stomach lead to interruption of its receptive relaxation which results in rapid emptying of liquid, then lead to dumping syndrome that could be overcome by suitable dietary measures.

Radovanovi et al. [8] showed that vagotomy with gastrojejunostomy is considered a safe and feasible surgical procedure which has good functional results regarding less incidence of ulcer recurrence, and low rate of postoperative side effects.

Recently many surgeons prefer simple ulcer closure and suture ligation of the bleeding vessels more than definite ulcer surgery due to improvement of medical therapy. But, in patients with failed medical treatment, definite ulcer surgery with truncal vagotomy and gastrojejunostomy was a good choice for improving surgical outcomes [15].

\section{Conclusion}

Perforated peptic ulcer is a serious surgical problem that has high rates of morbidity and mortality. Early diagnosis and management could improve patients' outcome. Due to advancement of medical therapies against $H$. pylori infection and therapies that lead to long term acid inhibition, definitive ulcer surgery rate has declined markedly except for fit young patients with good general condition who presented early but in old unfit patients with co-morbid conditions only sealing of the perforation with omental patch followed by medical therapy for eradication of $H$. pylori and for inhibition of acid secretion could be better recent management strategy.

\section{Limitations of the Study}

The limitations of the current study are the small number of cases and shorter 
period of follow-up.

\section{Conflicts of Interest}

The authors declare no conflicts of interest regarding the publication of this paper.

\section{References}

[1] Arora, B.K., Arora, R. and Arora, A. (2017) Modified Graham's Repair for Peptic Ulcer Perforation: Reassessment Study. International Surgery Journal, 4, 1667-1671. https://doi.org/10.18203/2349-2902.isj20171618

[2] Berne, T.V. and Donovan, A.J. (1989) Nonoperative Treatment of Perforated Duodenal Ulcer. The Archives of Surgery, 124, 830-832. https://doi.org/10.1001/archsurg.1989.01410070084017

[3] Testini, M., Portincasa, P., Piccinni, G., Lissidini, G., Pellegrini, F. and Greco, L. (2003) Significant Factors Associated with Fatal Outcome in Emergency Open Surgery for Perforated Peptic Ulcer. World Journal of Gastroenterology, 9, 2338-2340. https://doi.org/10.3748/wjg.v9.i10.2338

[4] Hill, A.G. (2001) The Management of Perforated Peptic Ulcer in a Resource Poor Environment. East African Medical Journal, 78, 346-348. https://doi.org/10.4314/eamj.v78i7.9005

[5] Budzynski, P., Pedziwiatr, M., Grzesiak-Kuik, A., Natkaniec, M., Major, P., Matlok, M., et al. (2015) Changing Patterns in the Surgical Treatment of Perforated Duodenal Ulcer-Single Centre Experience. Wideochirurgia I Inne Techniki Małoinwazyjne, 10, 430-436. https://doi.org/10.5114/wiitm.2015.54057

[6] Gutierrez, L., Pena, C., Merquez, R., Fakih, F., Adame, E. and Medina, J. (2000) Simple Closure or Vagotomy and Pyloroplasty for the Treatment of a Perforated Duodenal Ulcer Comparison of Results. Digestive Surgery, 17, 225-228.

https://doi.org/10.1159/000018839

[7] Shah, P.H. and Panchal, H.A. (2016) Acute Peptic Perforation: Clinical Profile and Our Experience with Operative Outcome. International Surgery Journal, 3, 2227-2232. https://doi.org/10.18203/2349-2902.isj20163606

[8] Radovanovi, N., Simi, A., Skrobi, O., Kotarac, M. and Ivanovi, N. (2014) Highly Selective Vagotomy and Gastrojejunostomy in the Treatment of Peptic Ulcer Induced Gastric Outlet Obstruction. Vojnosanitetski Pregled, 71, 1013-1017. https://doi.org/10.2298/VSP1411013R

[9] Chalya, P.L., Mabula, J.B., Koy, M., Mchembe, M.D., Jaka, H.M., Kabangila, R., Chandika, A.B. and Gilyoma, J.M. (2011) Clinical Profile and Outcome of Surgical Treatment of Perforated Peptic Ulcers in Northwestern Tanzania: A Tertiary Hospital Experience. World Journal of Emergency Surgery, 6, 31. https://doi.org/10.1186/1749-7922-6-31

[10] Khan, S.H., Aziz, S.A. and Ul-Haq, M.I. (2011) Perforated Peptic Ulcers: A Review of 36 Cases. The Professional Medical Journal, 18, 124-127.

[11] Nuhu, A., Madziga, A.G. and Gali, B.M. (2009) Acute Perforated Duodenal Ulcer in Maiduguri. The Internet Journal of Surgery, 21, 1.

[12] Satapathy, M.C., Dash, D. and Panda, C. (2013) Modified Grahams' Omentopexy in Acute Perforation of First Part of Duodenum; A Tertiary Level Experience in South India. Saudi Surgical Journal, 1, 33-36. https://doi.org/10.4103/2320-3846.125032 
[13] Leeman, M.F., Skouras, C.H. and Paterson-Brown, S. (2013) The Management of Perforated Gastric Ulcers. International Journal of Surgery, 11, 322-324. https://doi.org/10.1016/j.ijsu.2013.02.010

[14] Chandra, S.S. and Kumar, S.S. (2008) Definitive or Conservative Surgery for Perforated Gastric Ulcer? An Unresolved Problem. International Journal of Surgery, 7, 136-139.

[15] Suh, J.W. and Jee, Y.S. (2015) Laparoscopic Truncal Vagotomy and Gatrojejunostomy for Pyloric Stenosis. The Journal of Minimally Invasive Surgery, 18, 48-52. https://doi.org/10.7602/jmis.2015.18.2.48 